\title{
Sistem Informasi Akademik Berbasis Web pada SMK (Sekolah Menengah Kejuruan) Teknologi Industri Pembangunan Cimahi
}

\author{
I Pangaribuan ${ }^{1}$, F Subakti ${ }^{2}$ \\ Program Studi Sistem Informasi, Universitas Komputer Indonesia ${ }^{1,2}$ \\ Jl. Dipatiukur No. 112-116, Bandung, 40132, Indonesia ${ }^{1,2}$ \\ e-mail: imelda@email.unikom.ac.id ${ }^{1 *}$,femisubekti@email.unikom.ac.id ${ }^{2}$, \\ diterima: 7 Juli 2019 \\ direvisi: 23 September 2019 \\ dipublikasi: 24 September 2019
}

\begin{abstract}
Abstrak
SMK Teknologi Industri Pembangunan Cimahi merupakan salah satu Lembaga Pendidikan swasta yang terletak di Kota Cimahi. Sistem informasi akademik yang sedang berjalan di SMK Teknlogi Industri Pembangunan Cimahi saat ini belum menggunakan sistem informasi yang terkomputerisasi sehingga memiliki kendala-kendala yang dihadapi seperti pada proses pendaftaran ulang siswa baru, proses penjadwalan kelas, dan proses penilaian siswa. Tujuan dari penelitian ini adalah merancang sistem informasi akademik yang mencakup pendaftaran, penjadwalan kelas dan penilaian. Metode yang digunakan pada penelitian ini adalah metode prototype untuk pengembangan sistem informasi, selain itu metode untuk analisis dan desain sistem menggunakan metode berorientasi objek. Dengan mengimpelementasikan sistem informasi akademik yang diusulkan ini, maka sangat diharapkan kegiatan akademik di SMK Teknologi Industri Pembangunan Cimahi dapat berjalan ancar dan dapat meminimalkan kendala - kendala dalam proses pendaftaran, penjadwalan dan penilaian.
\end{abstract}

Kata kunci : Sistem Informasi; Akademik; Sekolah Menengah Kejuruan

\begin{abstract}
Cimahi Industrial Development Vocational Technology is a private educational institution located in Cimahi City. The academic information system that is currently running at the Cimahi Development Industry Technical Vocational School currently does not use a computerized information system so that it has constraints faced such as the re-registration process for new students, the class scheduling process, and the student assessment process. The purpose of this study is to design an academic information system that includes registration, class scheduling and assessment. The method used in this research is the prototype method for the development of information systems, in addition to the method for analysis and system design using object-oriented methods. By implementing this proposed academic information system, it is expected that academic activities at the Cimahi Industrial Technology Development Vocational School can run dangerously and can minimize obstacles in the process of registration, scheduling and assessment.
\end{abstract}

Keywords: Information Systems; Academic; Vocational High Schools

\section{Pendahuluan}

Sistem Informasi Akademik adalah sistem yang menyediakan layanan yaitu sebuah informasi data akademik yang dirancang sesuai dengan proses bisnis yang berjalan untuk meningkatkan kinerja dan kualitas pelayanan akademik. Dimana dalam hal ini pelayanan 
yang diberikan yaitu seperti: penyimpanan data untuk siswa baru, penentuan kelas, penentuan jadwal pelajaran, pembuatan jadwal mengajar, pembagian wali kelas, proses penilaian.[1]

Sistem informasi akademik merupakan sistem yang dibangun guna mempermudah dalam menjalankan hal-hal yang berkaitan dengan kegiatan administrasi akademik di lembaga pendidikan dan dilaksanakan secara daring. Beberapa aktivitas administratif adalah penerimaan siswa baru, penjadwalan, pengelolaan data pengajar/guru, karyawan, siswa, pengelolaan nilai dan sebagainya. Sistem Informasi akademik diharapkan dapat membantu dalam proses pengambilan keputusan. Pengembangan teknologi informasi saat ini sudah banyak sekali diimplementasikan dalam bidang akademik yang mengarah kepada aplikasi berbasis web sebagai media semua data dan informasi yang terdapat pada sistem untuk ditampilkan dengan menggunakan jaringan internet, pemanfaatan teknologi di Sekolah Menengah Kejuruan sangat dibutuhkan agar dapat meningkatkan produktivitas dan efisiensi untuk SMK itu sendiri baik dalam sistem administrasinya dan sistem akademiknya itu sendiri.

Terdapat beberapa kendala-kendala yang dihadapi oleh pihak sekolah SMK Teknologi Industri Cimahi seperti pada proses pendaftaran siswa baru, dimana pihak sekolah masih menyediakan formulir pendaftaran siswa baru yang dicetak pada kertas yang hanya dapat diambil oleh calon siswa pada saat hari dan jam sekolah saja, kemudian pada proses penjadwalan kelas sering terjadi bentrokan dari segi waktu, dimana saat ini SMK Teknologi Industri Pembangunan Cimahi memiliki tiga kampus dengan alamat yang berbeda-beda sebagai tempat terlaksananya kegiatan belajar dan mengajar, sehingga kegiatan operasional sekolah seperti pembelajarannya menggunakan sistem moving class. Kemudian pada proses pembuatan rapot terdapat kendala lain yaitu rapot dibuat dengan format yang baru berdasarkan kurikulum 2013 hal ini menyebabkan banyak wali kelas yang tidak sanggup membuat rapor dengan format baru tersebut karena menggunakan predikat dan deskripsi untuk satu siswa dengan satu mata pelajaran sedangkan banyak guru yang menyerahkan data nilai siswa kepada wali kelas dalam kurun waktu yang dekat dengan hari pembagian rapor sehingga pembuatan rapor dilakukan oleh pihak Tata Usaha.

Berdasarkan penelitian sebelumnya oleh Imelda dan Erik [2], sistem informasi akademik berbasis web dapat membantu dalam mempermudah pencarian data dan meningkatkan efisiensi dalam pembuatan laporan. Menurut Fabriyan Fandi Dwi Imaniawan, Andi Dwi Riyanto [3] dengan adanya sistem informasi akademik, segala informasi yang berkaitan dengan proses akademik seperti daftar nilai, jadwal, dan sebagainya, dapat diakses dengan mudah dan cepat sehingga mampu mengefektifkan waktu dan mengefisienkan biaya.

Tujuan dari penelitian ini adalah untuk menganalisis sistem yang berjalan di SMK Teknologi Industri Pembangunan Cimahi, berdasarkan hasil analisis dilakukan perancangan sistem informasi akademik di SMK Teknologi Industri Pembangunan Cimahi. Metode yang digunakan untuk mengumpulkan data adalah observasi dan wawancara sedangkan metode analisis dan perancangan pada penelitian ini adalah metode analisis dan perancangan berorientasi objek (OOAD), sedangkan metode pengembangan sistemnya menggunakan metode prototype. Manfaat dari penelitian adalah menyediakan suatu sistem informasi akademik yang dapat membantu SMK Teknologi Industri Cimahi dalam hal pendaftaran siswa baru, penjadwalan, pembuatan rapot sesuai kurikulum 2013.

\section{Kajian Pustaka}

2.1 Pengertian Sistem

Sistem merupakan suatu kelompok elemen yang saling berhubungan dan memiliki fungsi untuk menggapai suatu tujuan bersama [4]. 


\subsection{Pengertian Informasi}

Informasi merupakan data-data yang diproses sedemikian rupa sehingga memiliki maksud dan tujuan bagi setiap orang yang membutuhkan informasi tersebut [4].

\subsection{Pengertian Akademik}

Akademik merupakan kegiatan-kegiatan yang berhubungan dengan pendidikan secara umum guna menghasilkan informasi yang berhubungan dalam kegiatan pendidikan [5].

\subsection{Pengertian Sistem Informasi Akademik}

Sistem informasi akademik merupakan suatu kelompok elemen yang saling terhubung satu dengan lainnya, guna memproses data akademik menjadi suatu informasi yang berguna bagi penggunanya [6].

\subsection{Metode Prototipe}

Menurut Ogedebe prototype merupakan metode pengembangan perangkat lunak berupa model fisik sistem dan berfungsi sebagai versi awal sistem [7]. Agar proses berhasil dengan baik, maka perlu di defenisikan aturan - aturan pada tahap awal yaitu pengembang dan pengguna harus satu pemahaman bahwa prototype dibangun untuk mendefenisikan kebutuhan awal. Prototype akan dihilangkan atau ditambahkan pada bagiannya sehingga sesuai dengan perencanaan dan analisis yang dilakukan oleh pengembang sampai dengan ujicoba dilakukan secara simultan seiring dengan proses pengembangan. Langkah-langkah dalam prototyping adalah sebagai berikut: 1. Pengumpulan Kebutuhan. 2. Proses desain yang cepat. 3. Membangun prototipe. 4. Evaluasi dan perbaikan

\subsection{Metode Analisis dan Perancangan Berorientasi Objek}

Menurut Meinarini dan widyanasri [8] merupakan alat terbaik yang dapat digunakan untuk sebuah proyek yang akan mengimplementasikan sistem yang menggunakan teknologi objek untuk membangun, mengelola dan merakit objek - objek itu menjadi aplikasi yang berguna

\subsection{Unified Modelling Language (UML)}

UML(Unified Modeling Language) merupakan visualisasi kontruksi dari desain berorientasi objek. Menurut Kendall \& Kendall [9] mengatakan bahwa "UML approach is well worth invesgating and understanding, due to its wide acceptance and usage". UML menvisualisasikan kontruksi sistem ke dalam beberapa diagram yang sering digunakan yaitu diagram use case, diagram aktivitas, dan diagram kelas. Adapun desain sistem seringkali dilengkapi dengan desain forminput outputuntuk memudahkan pemahaman programmer.

\section{Metode Penelitian}

Metode penelitian berisi tentang tahapan-tahapan yang dilakukan oleh penulis dalam proses penyusunan penelitian ini. Bagan alur pemikiran dibuat agar tujuan dari penelitian ini dapat tercapai. Dalam penelitian ini, langkah-langkah yang dilakukan yaitu meliputi desain penelitian, pengumpulan data, analisis, merancang, dan pengujian software.

3.1 Metode Pengumpulan Data

Metode observasi digunakan sebagai metode pengumpulan data di SMK Teknologi Industri Pembangunan Cimahi dan melakukan wawancara terhadap Kepala Tata Usaha, Bidang Kurikulum, dan Ketua Kompetensi Keahlian Teknik Komputer dan Jaringan, guna mendapatkan data-data primer. Selain itu peneliti juga memperoleh dokumen- 
dokumen seperti formulir peserta didik baru, buku pendaftaran, rekapitulasi keadaan peserta didik baru, data penjadwalan kelas, daftar hadir siswa, rekap absen siswa, dan rapor siswa sebagai data sekunder.

3.2 Metode Analisis dan Perancangan Sistem

Penelitian ini menggunakan metode pendekatan sistem berorientasi objek dan metode pengembangan sistem prototype. Alat bantu yang digunakan untuk perancangan sistem yang diusulkan yaitu Use Case Diagram, Skenario use case, Activity Diagram, Sequence Diagram, Class Diagram, Object Diagram, Component Diagram, dan Deployment Diagram.

\subsection{Penelitian Terkait}

\section{Hasil dan Pembahasan}

Berdasarkan penelitian sebelumnya yaitu penelitian Maryona dkk di SMAN 3Lubuk Basung menemukan berbagai kendala yang dialami oleh SMAN 3 Lubuk Basung, diantaranya adalah sistem informasi penjadwalan mata pelajaran siswa, jadwal mengajar guru, data siswa dan data guru yang masih manual.Sistem penjadwalan mata pelajaran siswa dan jadwal mengajar guru masih banyak kekurangan, karena belum tersedianya dalam bentuk database tetapi masih menggunakan lembaran kertas yang ditempelkan di papan pengumuman. Jadwal matapelajaran siswa dan jadwal mengajar guru dapat berubah-ubah terutama di awal semester atau di awal tahun pembelajaran. Hal ini membuat siswa dan guru menjadi bingung, karena jadwal yang tidak pasti, akibatnya siswa dan guru harus menunggu pihak sekolah untuk menempelkan jadwal mata pelajaran di papan pengumuman. Guru juga mengalami kesulitan dalam proses pembelajaran karena siswa kurang mendapatkan bahan ajar. Bahan ajar yang diberikan guru dalam bentuk buku pedoman, namun tidak semua materi terdapat dalam buku tersebut tetapi hanya berupa garis besar dari materi dan sedikit pembahasan materi saja. Sehingga guru menyampaikan materi secara lebih rinci di dalam kelas. Permasalahan lainyaadalah sistem informasi data siswa dan data guru belum tersediadalam bentuk database,tapi masih menggunakan lembaran kertasyang diminta kepada siswa dan guru,kemudian diinputkan oleh pegawai tata usaha. Proses ini membutuhkan waktu lama yang diawali dengan meminta data ke siswa dan guru kemudian diberikan kepada pegawai tata usaha. Sebagai solusi terhadap masalah diatas diusulkan system informasi akademik berbasis web yang mempermudah akses informasi kapan saja dan dimana saja. [10]

\subsection{Perancangan Sistem}

Perancangan sistem informasi akademik berbasis web ini dibuat untuk mengambarkan perancangan sistem yang diusulkan mulai dari halaman pendaftaran dan pendaftaran ulang, pembuatan kelas, penjadwalan, absensi, penilaian. Perancangan digambarkan menggunakan diagram usecase yang di gambarkan pada gambar 1 .

\subsection{Tujuan Perancangan Sistem}

Tujuan dari perancangan sistem informasi akademik ini yaitu untuk membuat sitem informasi akademik yang dapat menyimpan data calon siswa baru pada saat proses penerimaan peserta didik baru hingga data calon siswa baru tersebut bisa menjadi data siswa baru, selain itu sistem informasi akademik ini dapat membuat proses penjadwalan tanpa adanya bentrokan dari segi waktu, tempat, dan persetujuan setiap guru, kemudian sistem informasi akademik ini dapat mencetak rapor siswa dengan format baru yang sesuai dengan kurikulum 2013. 


\subsection{Gambaran Umum Sistem yang Diusulkan}

Sistem informasi akademik yang diusulkan dibuat agar dapat mengolah data pendaftaran calon siswa baru pada saat sekolah mengadakan program penerimaan peserta didik baru tiap tahunnya, kemudian sistem informasi akademik ini dapat mengolah data untuk pembuatan kelas, penjadwalan, absensi siswa, dan penilaian siswa, selain itu sistem informasi akademik yang diusulkan ini tidak hanya digunakan oleh staf dan guru yang ada disekolah, akan tetapi sistem ini dapat digunakan oleh seluruh siswa untuk melihat jadwal mata pelajaran dan riwayat penilaian dan Aktor yang terlibat dalam sistem didefinisikan pada tabel 1 .

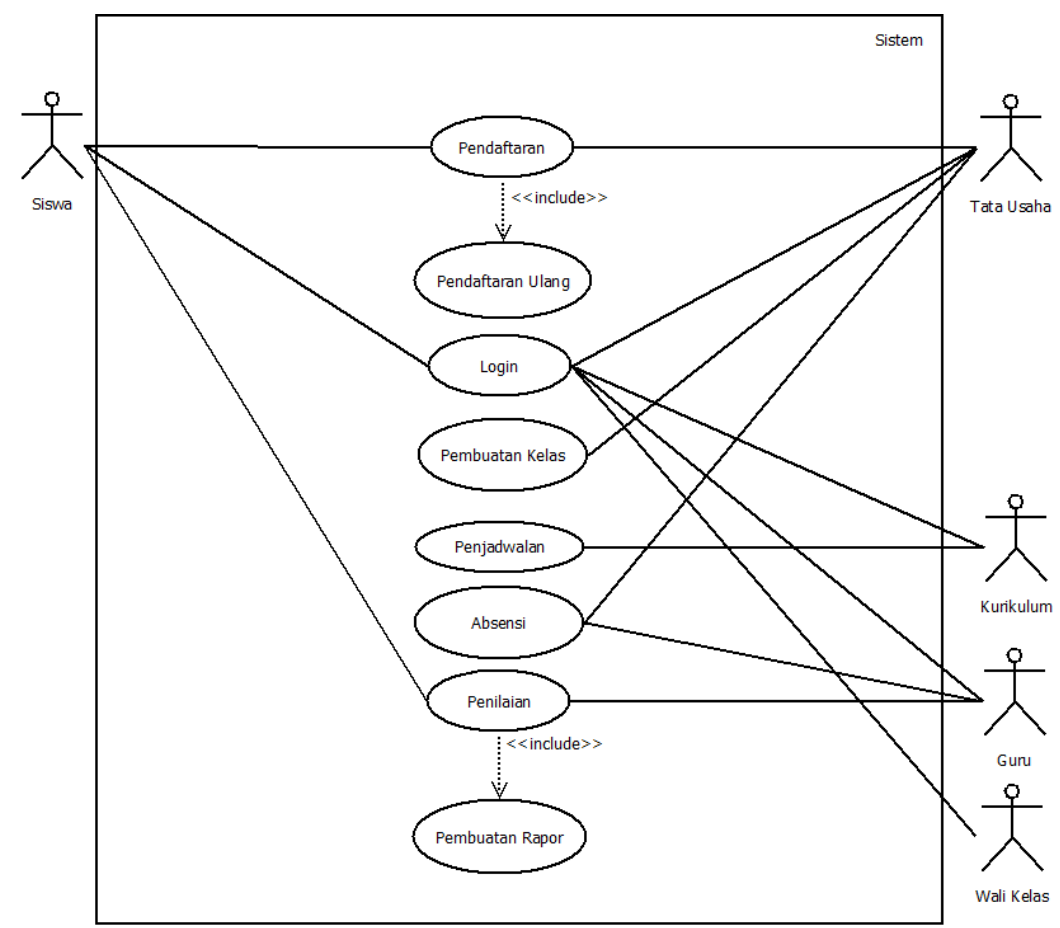

Gambar 1. Use Case Diagram

Tabel 1. Definisi aktor dan deskripsi

\begin{tabular}{|c|l|l|}
\hline No & \multicolumn{1}{|c|}{ User } & \multicolumn{1}{c|}{ Deskripsi } \\
\hline 1 & Siswa & $\begin{array}{l}\text { Orang yang berperan sebagai anak didik dan calon anak didik di } \\
\text { SMK Teknologi Industri Pembangunan Cimahi }\end{array}$ \\
\hline 2 & Tata Usaha & $\begin{array}{l}\text { Pihak yang bertugas mengelola seluruh aktivitas pendaftaran siswa } \\
\text { baru dan ikut terlibat dalam aktivitas penjadwalan, dan absensi }\end{array}$ \\
\hline 3 & Kurikulum & Pihak yang bertugas mengelola seluruh aktivitas penjadwalan \\
\hline 4 & Wali Kelas & $\begin{array}{l}\text { Orang yang bertugas untuk membuatkan dan memberikan rapor } \\
\text { siswa }\end{array}$ \\
\hline 5 & Guru & Orang yang bertugas memberikan nilai terhadap siswa \\
\hline
\end{tabular}

1) Implementasi Perangkat Lunak

- Sistem Operasi Microsoft Windows 7, 8, 8.1, 10;

- Web browser support PHP5, Javascript, dan CSS;

- Web server Apache 2.4.33;

- MySQL ver 10.

2) Implementasi Perangkat Keras

- Prosesor minimal Intel ${ }^{\circledR}$ Core $^{\mathrm{TM}} 2$ Duo; 
- RAM 2GB DDR3 atau lebih;

- Harddisk 120GB atau lebih;

- Wi-Fi Adapter $802.11 \mathrm{n} / \mathrm{b} / \mathrm{g}$;

- Mouse, keyboard, monitor dan printer.

3) Implementasi Antar Muka

Berikut ini merupakan tampilan antarmuka dari sistem informasi akademik berbasis web yang penulis rancang untuk diterapkan pada SMK Teknologi Industri Pembangunan Cimahi.

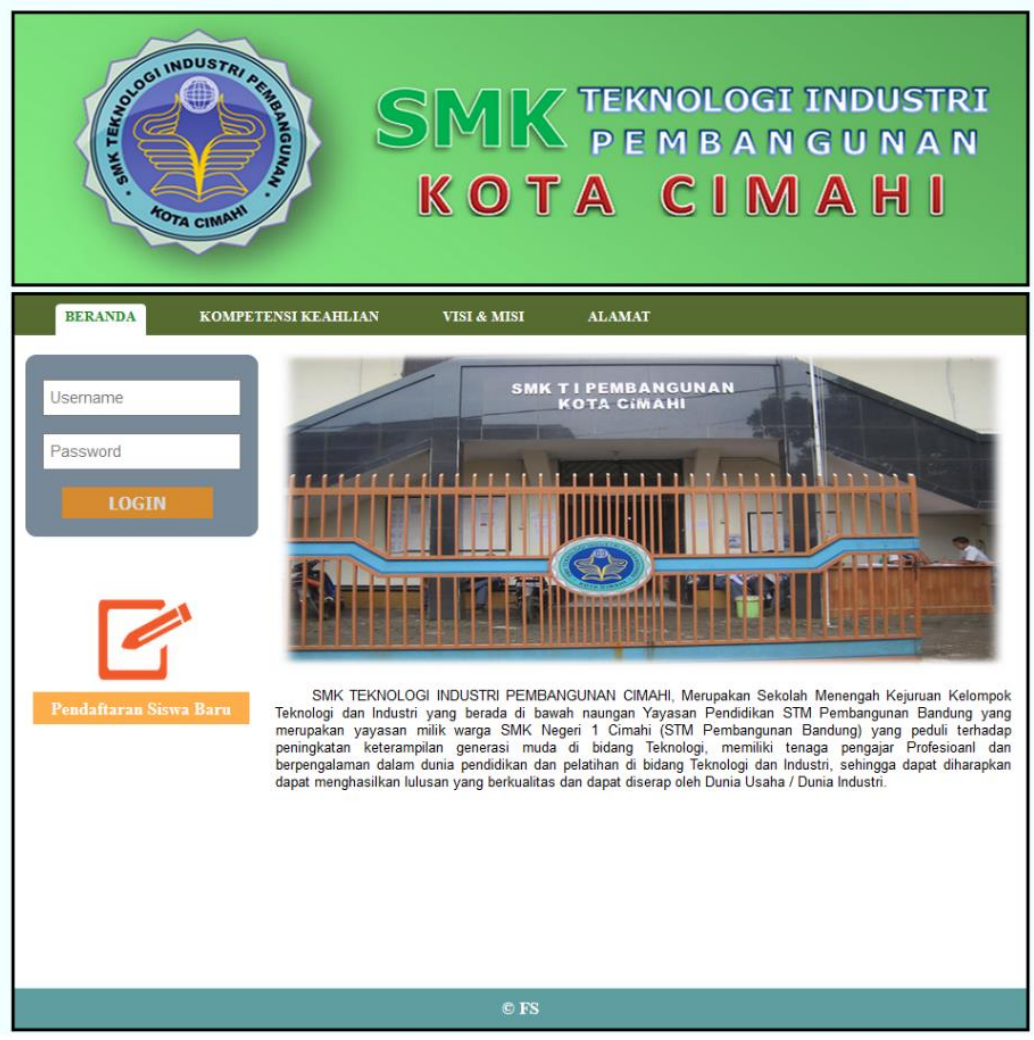

Gambar 2. Halaman Home

Gambar 2 merupakan halaman home program pada saat pertama kali dijalankan, pada halaman ini terdapat form login dan button untuk membuka form pendaftaran siswa baru. 


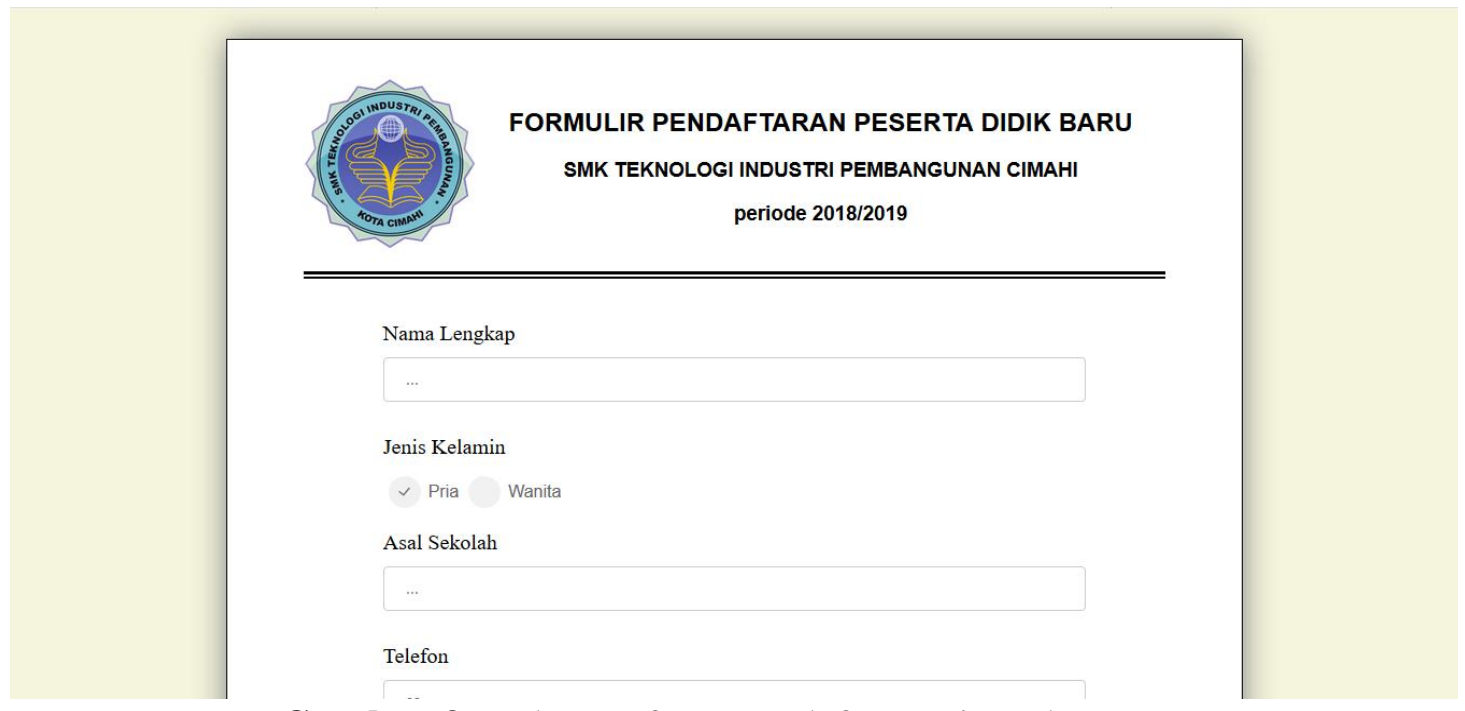

Gambar 3. Halaman form pendaftaran siswa baru

Gambar 3 merupakan halaman form pendaftaran siswa baru, halaman ini akan diinputkan biodata oleh calon siswa baru.

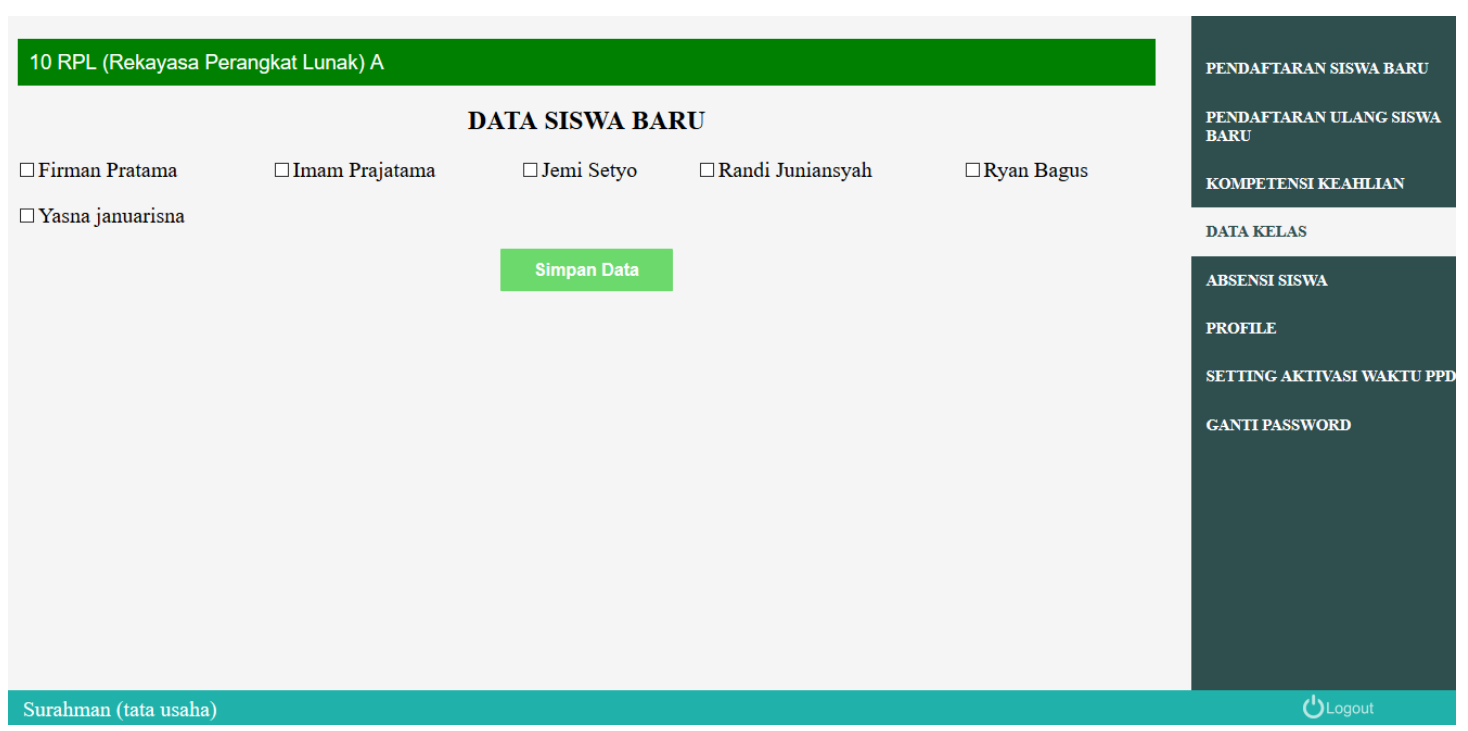

Gambar 4. Halaman pembuatan kelas

Gambar 4 merupakan halaman pembuatan kelas, dimana halaman ini hanya dapat diakses oleh pihak tata usaha, nama-nama calon siswa yang tersedia pada data data siswa baru merupakan nama-nama calon siswa yang sudah melakukan pembayaran secara lunas pada saat melakukan pendaftaran ulang. 


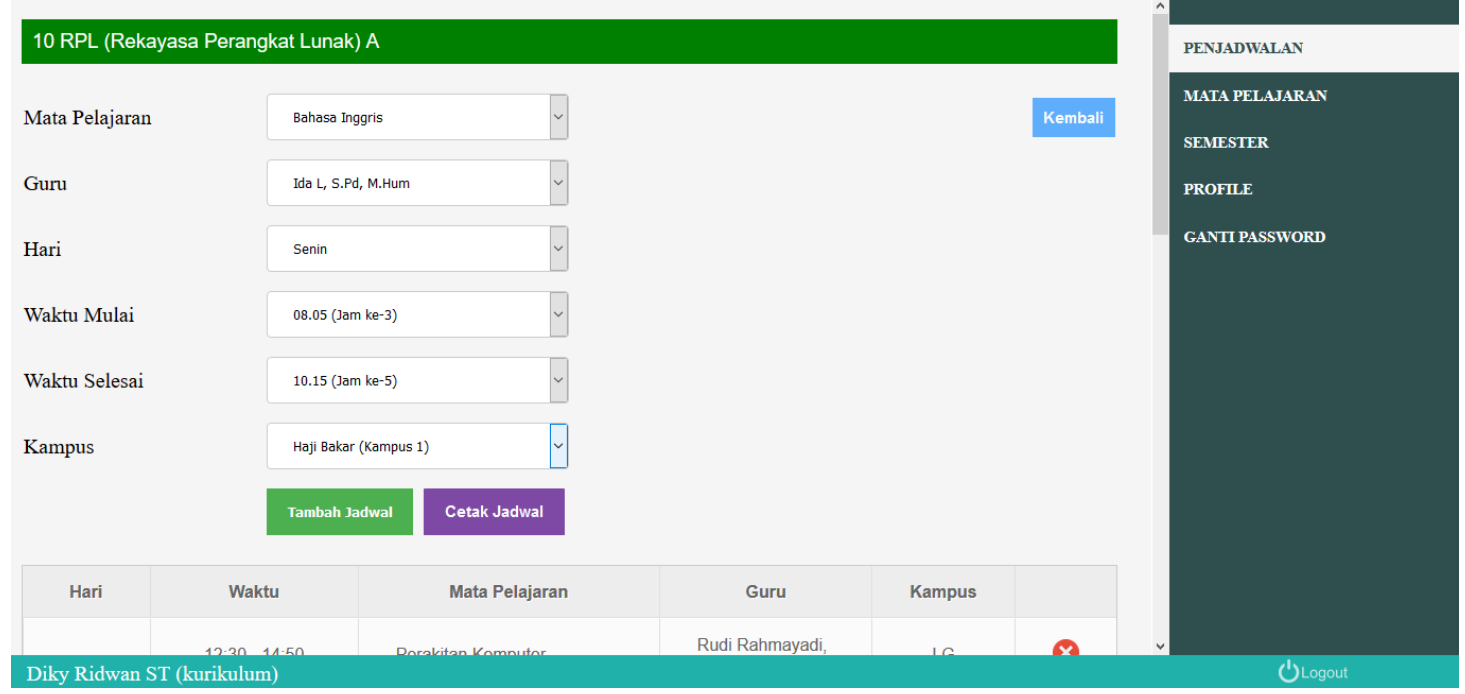

Gambar 5. Halaman penjadwalan

Gambar 5 merupakan halaman penjadwalan, dimana halaman ini hanya dapat diakses oleh pihak kurikulum, pada halaman tersebut tersedia form input untuk membuat jadwal tiap kelas.

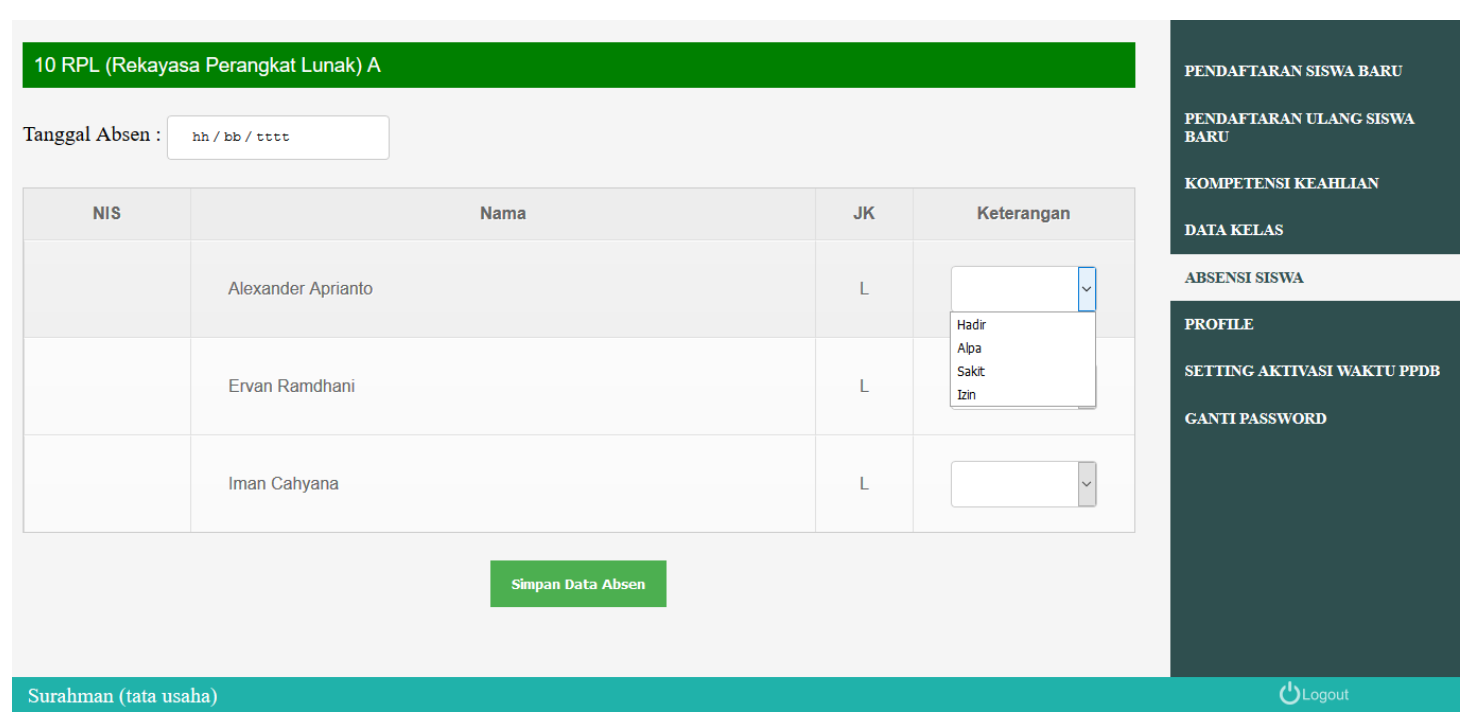

Gambar 6. Halaman absensi siswa

Gambar 6 merupakan halaman absensi siswa, dimana halaman ini hanya dapat diakses oleh pihak tata usaha, pada halaman ini pihak tata usaha akan menginputkan data absen siswa setiap minggu. 


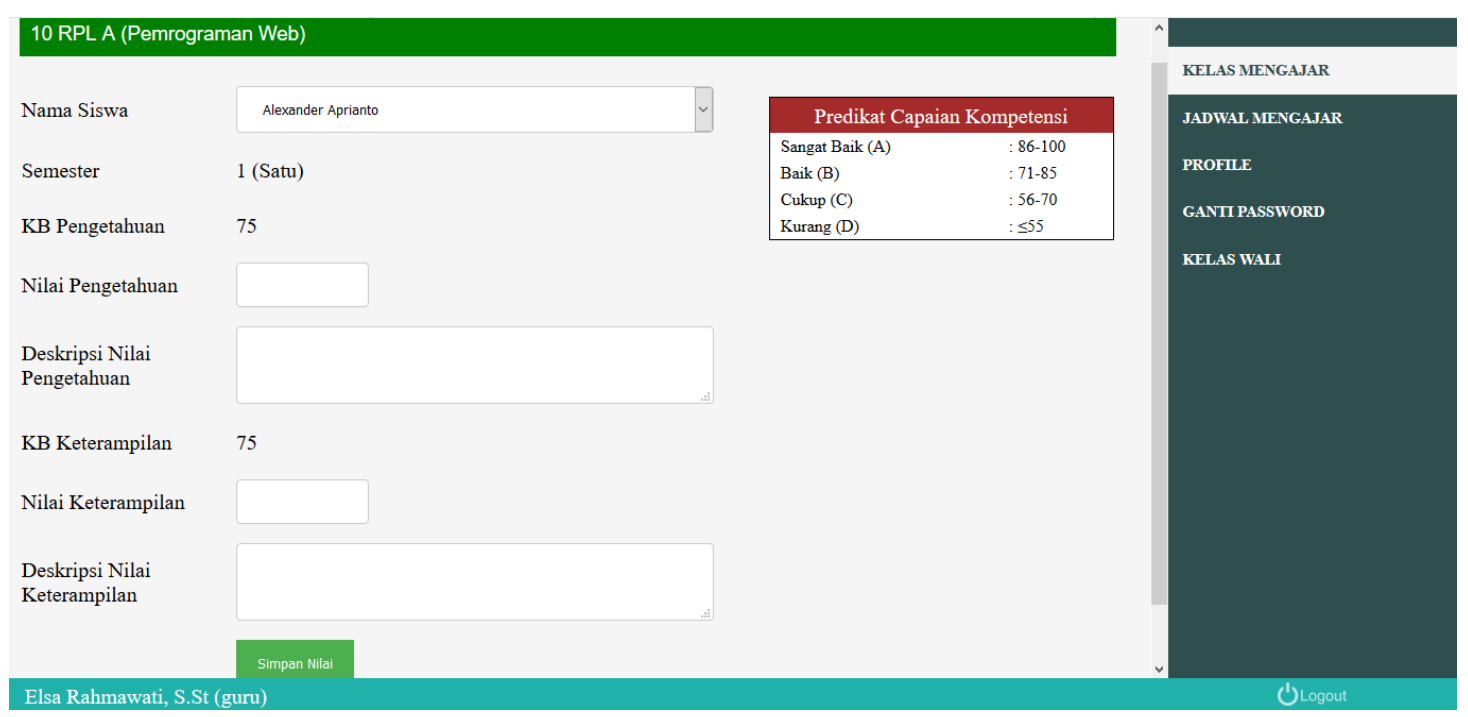

Gambar 7. Halaman form penilaian siswa

Gambar 7 merupakan halaman form penilaian siswa, dimana halaman ini dapat hanya dapat diakses oleh setiap guru termasuk wali kelas, data nilai siswa yang diinputkan melalui halaman ini akan dijadikan sebagai rapor siswa setiap semester.

\section{Kesimpulan}

Kesimpulan yang dapat diambil dari penelitian ini yaitu dengan adanya sistem informasi akademik berbasis web pada SMK Teknologi Industri Pembangunan Cimahi dapat mempermudah pihak tata usaha pada saat melakukan pengecekan persyaratan pendaftaran siswa baru, dan dapat mempersingkat waktu rekapitulasi data calon siswa, selain itu bagian kurikulum dapat dengan mudah melakukan pembuatan penjadwalan mata pelajaran setiap kelas tanpa adanya bentrokan, kemudian untuk seluruh guru dapat dengan mudah menginputkan data penilaian siswa yang terintegrasi dengan basis data sehingga setiap wali kelas bisa mencetak rapor tanpa harus menyalin data nilai yang diberikan oleh setiap guru. Sarana prasarana pembelajaran sekolah akan terus mengalami perkembangan dan perubahan, maka dari itu saran dari penulis untuk penelitian ini adalah pada proses penjadwalan belum tercantum detail mengenai ruangan yang ditempati oleh setiap kelas karena kondisi pembelajaran saat ini masih menggunakan sistem moving class, sehingga untuk penempatan ruangannya masih sangat fleksibel. Maka dari itu perlu adanya pengembangan penelitian lebih lanjut agar sistem informasi akademik di SMK Teknologi Industri Pembangunan Cimahi dapat menjadi lebih baik lagi dari apa yang sudah penulis lakukan.

\section{Ucapan Terima Kasih}

Bagian ini bersifat opsional. Apabila ada, maka ucapan terima kasih ditujukan kepada pihak-pihak yang terlibat dalam penelitian (misalnya pihak pada proses perizinan, pengumpulan data, dll) ataupun pada institusi yang telah memberi dukungan financial terhadap penelitian anda.

\section{Daftar Pustaka}

[1] Sita Marlina, Magnaz Lestira Oktaroza and Nunung Nurhayati, "Perancangan Sistem Informasi Akademik di SMA Alfa Centauri Bandung," Prosiding Akuntansi, vol. 5, no. 1, pp.76 - 82, 2019. Available : http://karyailmiah. unisba. ac.id/index.php/akuntansi/issue/view/220 [Accessed: 22-Aug-2019] 
[2] Imelda and Erik, "Perancangan Sistem Informasi Akademik pada Sekolah Dasar Negeri Sukajadi 9 Bandung," JATI, vol. 3, no. 1, pp. 45 - 59, 2014. Available: http://jati.is.unikom.ac.id/jurnal/perancangan-sistem-informasi.1i [Accessed: 22-Aug2019]

[3] Fabriyan Fandi Dwi Imaniawan and Andi Dwi Riyanto, "Perancangan Sistem Informasi Akademik Berbasis Web Pada Akademi Pertanian Hkti Banyumas," Telematika, Vol 8, No. 1, pp. 43 - 54, 2019.

[4] A. Kristanto, Perancangan Sistem Informasi dan Aplikasinya, Yogyakarta : Gava Media, 2008

[5] Mia Fitriawati, Sistem Informasi Akademik Di SMP Negeri 10 Cimahi, Jurnal Teknologi dan Informasi (JATI), vol. 4, no. 2, pp. 1-11, 2014

[6] Marliana B. Winanti dan Endry Prayoga, Sistem Informasi Akademik Berbasis Web Di SMA Tamansiswa Sukabumi, Jurnal Teknologi dan Informasi (JATI), vol. 3, no. 2, pp. 1-15, 2013.

[7] Ogedebe, P. M., \& Jacob, B.P., "Software Prototyping: A Strategy to Use When User Lacks Data Processing Experience. " ARPN Journal of Systems and Software. Vol. 2, N0.6 http://scientificjournals.org/journalofsystemsandsoftware/archive/vol2no6/vol2no6_4 .pdf, [Accessed: 22-Aug-2019]

[8] M C Utami dan W Shelawaty, "Analisis dan Perancangan Sistem Informasi Administrasi dan Kepesertaan Askes di PT. Askes (Persero) KCU Bandung." Studia Informatika : Jurnal Sistem Informasi. Vol 7, No. 1 pp. 1 - 4, 2014. [Accessed: 22Aug-2019]

[9] M Susilowati dan H P Prasetija, “Analisis dan Desain Berorientasi Objek pada Sistem Informasi Administrasi Keuangan Akademik Online, " SNIK, pp. 161 - 168, 2016 , Available :https://ilkom.unnes.ac.id/snik/prosiding/2016/25.\%20SNIK_270_Analisis\%20dan\% 20Desain.pdf

[10] Maryona S, Arnita dan A Kairi, "Perancangan Sistem Informasi Akademik Berbasis Web Di Sma Negeri 3 Lubuk Basung" ejurnal Bunghata, Available : http://ejurnal.bunghatta.ac.id/index.php?journal=JFKIP\&page=article\&op=viewFile \&path[]=6098\&path[]=5152 [Accessed: 22-Aug-2019] 